\title{
Reflexões a respeito de uma experiência de participação infantil no Brasil envolvendo os espaços urbanos e a perspectiva das crianças
}

\author{
Fabiana de Oliveira ${ }^{\mathrm{i}}$
}

Universidade Federal de Alfenas, Brasil

\section{Resumo}

O presente artigo tem como objetivo refletir acerca da participação infantil a partir das ações desenvolvidas por uma organização não governamental brasileira. A pesquisa desenvolvida se caracteriza como qualitativa por meio da realização de um estudo bibliográfico e documental, com a consequente análise de conteúdo. Entende-se que, por meio dos Estudos da Criança, especialmente a partir das contribuições da Sociologia da Infância, será possível pensar em formas de atuação da criança na sociedade com base na compreensão dessa enquanto ator social, sujeito de direitos e com voz. A experiência brasileira que trouxemos nos aponta caminhos importantes na consideração da participação infantil nos espaços públicos, especificamente no espaço urbano das cidades. Os projetos desenvolvidos envolvendo as crianças e seus contextos de vida contribuem para a consideração dessas como cidadãs ativas e competentes e nos mostram que as mesmas estão bastante atentas ao espaço que as rodeia.

Palavras-chave

Participação infantil; Direitos; Criança; Infância

\section{Introdução}

O presente artigo tem como objetivo refletir acerca da participação infantil a partir das ações desenvolvidas por uma organização não 
governamental brasileira. É sabido que, em muitos países, o espaço de atuação dessas organizações cresce a cada dia. Essas, por sua vez, têm desenvolvido ações que visam contribuir para o campo da participação infantil - como é o caso, por exemplo, do Centro de Criação de Imagem popular (CECIP), da AVANTE ou da Rede Nacional pela Primeira Infância (RNPI).

Para a presente reflexão, pautamo-nos nas ações desenvolvidas pelo CECIP a partir de seu projeto denominado "Criança Pequena em Foco". O CECIP é uma organização da sociedade civil e que desde sua criação, em 1986, vem desenvolvendo iniciativas em prol do fortalecimento da cidadania. Nesse sentido, a organização apoia e defende projetos voltados às crianças, especialmente aqueles dedicados à participação infantil cidadã. Em função do desenvolvimento desses projetos, o CECIP foi escolhido e é, inclusive, responsável pela iniciativa do " $1{ }^{\circ}$ Prêmio Nacional de Projetos de Participação Infantil", de 2014. Esse reconhecimento premiou sete iniciativas nacionais que tiveram como foco projetos que consideraram crianças em todas as suas fases de execução e com relacionamento direto com seu contexto imediato. Os projetos buscaram contribuir para a transformação dos espaços públicos e da compreensão da criança como cidadã competente, capaz e que deve ser levada em consideração.

Com o intuito de discutir a participação infantil por meio das atividades realizadas por essa ONG, propusemos questões norteadoras para esta reflexão: a) quais as possibilidades de participação infantil as crianças têm vivenciado?; e b) quais as mudanças necessárias na relação entre adultos e crianças para que essas possam participar dos processos que as afetam? A presente reflexão buscará responder esses questionamentos centrais para a discussão atual do campo teórico, o qual concebe a criança e sua participação nos vários âmbitos da sociedade como ator social, principalmente na organização dos espaços públicos. Essa participação se configura como uma participação política das crianças consideradas como cidadãs.

A partir dos Estudos da Criança, entende-se que, especialmente no que diz respeito às contribuições da Sociologia da Infância, será possível pensar em formas de atuação da criança na sociedade a partir da compreensão dessa como ator social, sujeito de direitos e com voz. Os Estudos da Criança reivindicam a retirada da criança de um lugar menor - até então conferido a ela pelo paradigma tradicional das ciências sociais e da 
psicologia -, tendo como um de seus questionamentos centrais o conceito de socialização baseado em uma perspectiva funcionalista, a partir das proposições de Durkheim. As concepções atuais sobre a socialização das crianças concordam que esse fenômeno ocorre por meio de múltiplas negociações com seus pares e também com os adultos, contribuindo, assim, para a construção da identidade do sujeito (Plaisance, 2004; Sirota, 2001; Mollo-Bouvier, 2005).

A partir dos anos 80 do século $\mathrm{XX}$, os trabalhos sociológicos sobre a infância se multiplicaram e foram sendo modificados. As pesquisas voltadas para a compreensão das relações entre as crianças, as quais buscavam novos caminhos para além de uma perspectiva reprodutiva da socialização, foram as que mais sofreram com essas modificações. Nesse sentido, surgiram várias publicações em revistas especializadas, como a Sociological Studies of Children, e outras não especializadas em assuntos da infância. Além disso, outras obras começaram a aparecer, como foi o caso das publicações de Corsaro (1997), Cunningham (1991), James (1990), Prout (1990), Jenks (1982) e Qvortrup (1994), entre outros (cit. por Montandon, 2001).

Os Estudos da Criança se caracterizam por terem uma abordagem multidisciplinar, justificando as heterogeneidades dentro desse campo, mas há, também, aspectos centrais que são compartilhados, como, por exemplo: a) a compreensão da criança e da infância como uma construção social; b) a infância entendida não como algo universal, mas como um componente tanto estrutural quanto cultural; c) as crianças sendo consideradas atores em sentido pleno e não simplesmente como seres em devir; d) as crianças consideradas ao mesmo tempo produto e atores dos processos sociais; e) a infância como uma variável de análise sociológica que se articula à diversidade de vida das crianças, considerando-se classe social, gênero e pertencimento étnico (James \& Prout, 1990).

Entender a criança como um ator social pleno traz grandes desafios para o campo dos Estudos da Criança, principalmente no que se refere aos aspectos epistemológicos até então enraizados em uma concepção universal de criança - bem como no que diz respeito aos aspectos metodológicos que possam realmente contribuir para captar a voz e a perspectiva delas. Em relação à participação infantil, o desafio não é menor, já que pesquisas vêm 
demostrando que os impactos e os resultados da participação para as próprias crianças têm sido lentos (Taylor \& Percy-Smith, 2008). Assim, é preciso continuar refletindo acerca dos meios pelos quais a participação infantil tem sido efetivada e a forma como as crianças são inseridas nesses processos.

A presente discussão buscou responder esses questionamentos centrais para a discussão atual do campo teórico, a qual concebe a criança como ator social e considera sua participação nos vários âmbitos da sociedade, especificamente na organização dos espaços públicos. Essa participação é de cunho político, se consideramos as crianças como cidadãos.

Essa reflexão está organizada em três partes complementares, quais sejam: 1) um debate teórico envolvendo a discussão do conceito de participação infantil; 2) uma experiência de participação infantil baseada nas atividades da organização não governamental CECIP; e 3) algumas reflexões a respeito dos resultados obtidos pelos projetos de participação infantil dessa experiência brasileira.

\section{Pressupostos teóricos do campo da participação infantil}

Quando discutimos os aspectos relacionados à participação infantil, não podemos deixar de considerar as relações de poder dos adultos sobre as crianças, uma vez que esse trato balizará as possibilidades de participação das crianças na sociedade.

A discussão sobre a participação das crianças envolve uma complexidade de fatores, pois depende do desenvolvimento de capacidades e motivações e, também, do contexto cultural e particular de cada família. Assim, ao considerarmos a participação infantil que leva a um empoderamento das crianças, é preciso observar, também, o impacto disso na relação das crianças dentro de suas famílias - pois isso envolve uma revisão das práticas tradicionais dos pais em relação às crianças (Hart, 1992).

Os estudos de Hart (1992), Lansdown (2003) e Taylor e Percy-Smith (2008) apontam que os adultos têm fracassado ao propor projetos de participação infantil, pois em muitos casos abusam do poder sobre as crianças, pautando-se em uma perspectiva adulta, desconsiderando, assim, o melhor interesse do outro. Os adultos também consideram mais os direitos dos pais do que os das crianças. 
A perspectiva adulta baseia-se, frequentemente, em alguns argumentos que consideram haver uma falta de competência por parte das crianças para a participação social. Os adultos argumentam que as crianças devem aprender a ter responsabilidades antes de the serem dados direitos, fato que leva a uma compreensão equivocada, qual seja, se as crianças tivessem seus direitos de participação considerados, estariam indo além do que sua idade permite e, dessa forma, haveria uma perda da autoridade dos pais (Lansdown, 2003). Essa compreensão leva a uma "invizibilização" das crianças no espaço público, diminuindo drasticamente suas possibilidades de participação dos processos de tomada de decisão. Isso porque a criança é vista a partir da inferiorização de suas capacidades, as quais são avaliadas a partir de seu aspecto biológico: imatura, desprotegida e dependente do adulto. Essa relação produz uma dicotomização entre a noção da criança protegida e daquela com direito à participação.

Esta visão negativa da vulnerabilidade da criança leva a uma privação da realização dos direitos que Ihe assistem. Assim, ao considerarmos a tradicional distinção entre os direitos de proteção, provisão e participação, é possível comprovar, quando relacionada à aplicação do cumprimento dos direitos das crianças, que entre os direitos que há menos progresso em sua consideração é o que se refere à participação (Sarmento \& Pinto, 1997). Por isso, compreendemos que a efetivação dos direitos de participação das crianças envolve um processo de aprendizagem por parte de ambos, adultos e crianças. A participação infantil leva em consideração o questionamento de uma relação historicamente assimétrica entre esses dois grupos geracionais e precisa ser revista. Essa reavaliação virá da prática constante de participação das crianças por meio de um processo compartilhado de divisão de poder com os adultos (Hart, 1992; Lansdown, 2003). Nesse sentido, discutir a participação infantil se faz cada vez mais urgente para desmistificar esse conceito, o qual aparece de diversas formas na literatura baseado em conceituações que não chegam a um consenso sobre sua compreensão fato que também pode gerar práticas equivocadas no tocante à consideração da efetiva participação das crianças.

A discussão sobre participação infantil na América Latina tem sua origem nas experiências das crianças trabalhadoras das décadas de 60 e 70 do século $X X$ e nos esforços para que fossem reconhecidas como sujeitos 
sociais e políticos. Esses esforços provêm das fontes dos movimentos populares que lutam pelo reconhecimento dos seus direitos como os trabalhadores do campo, indígenas entre outros (Alfageme, Cantos, \&Martínez, 2003). A etimologia da palavra 'participação' vem do latim participatio que significa 'tomar parte'. As crianças fazem parte da sociedade, mas não Ihes foi dado o direito concreto de 'tomar parte' principalmente nos assuntos que a afetam diretamente. Na presente reflexão, compreendemos a participação infantil como

(...) um processo social o qual pretende que crianças e adolescentes desempenhem o papel principal no desenvolvimento de suas comunidades para alcançar a realização plena de seus direitos, atendendo, assim, os seus próprios interesses. É colocar em prática a visão das crianças como sujeitos de direitos. Para tanto, é necessário que haja uma redefinição dos papéis nos diferentes âmbitos da sociedade: infância e juventude, autoridades, famílias, sociedade civil, entidades, etc" (Gaitán, 1998, cit. por Alfageme et al., 2003, p. 48).

A partir dessa conceituação, consideramos que o processo de participação infantil envolve a tomada de decisão e a partilha das questões que afetam o grupo, visando, assim, a resolução de problemas os quais têm como atores principais as crianças, os jovens e a efetivação de seus direitos. Ou seja, contrapõe a uma participação simbólica e válida a capacidade das crianças de decidirem, analisarem, interpretarem, questionarem, proporem, atuarem, possibilitando-Ihes, assim, 'tomarem parte' dos projetos que the possam ser próximos e significativos.

A partir de um leque de possibilidades construído entre adultos e crianças, a participação das crianças pode se dar de diversas maneiras, como, por exemplo, nas famílias. Considerando que as crianças devem compreender a realidade do seu entorno, elas podem decidir a roupa que irão vestir e podem contribuir com decisões relacionadas à organização da casa e à alimentação. Quando pensamos nos assuntos administrativos, as crianças também devem participar, opinando a respeito dos processos legais de adoção, de suspensão e supressão da guarda materna ou paterna, levando em consideração o que mais lhes interessa. Também é possível incorporar a participação infantil nas escolas, por meio dos conselhos estudantis e clubes infantis (Suriel, 2006).

Uma tipologia bastante conhecida no cenário internacional a respeito da participação infantil é a Escada da Participação de Roger Hart. O autor 
apresenta as possibilidades de participação infantil por meio de níveis/estágios que são representados por uma escada denominada de Escada da Participação, com oito níveis, dos quais os três primeiros estão relacionados a uma participação de cunho 'decorativo', 'manipulativo', cuja denominação global pode ser 'tokenismo', que significaria uma não participação. Nesses primeiros níveis é 'dada voz' às crianças de forma aparente e não significativa, pois não são dadas oportunidades para que elas façam escolhas e formulem suas próprias decisões e, mesmo quando são ouvidas, suas vozes não produzem mudanças nem transformações nos eventos aos quais estão relacionadas. A partir do nível 4, a criança participaria de eventos de forma consentida, apresentando uma compreensão acerca das intenções do projeto, entendendo o significado de sua participação e os motivos pelos quais está envolvida no projeto. É importante ressaltar que em todos os níveis há a participação dos adultos, de modo a contribuir, seja de forma direta ou indireta, com as decisões tomadas pelas crianças no desenvolvimento das atividades planejadas.

Hart (1992) alerta sobre a importância da não consideração dos níveis presentes na Escada da Participação como uma simples forma de medir a participação das crianças em algum projeto. Na verdade, o que o autor propõe é uma forma de pensar os possíveis modos/cenários de participação nos quais as crianças são incluídas. No entanto, encontramos algumas críticas na literatura em relação a essa proposição de níveis presente na Escada da Participação. Alguns autores consideram que a ideia de sequência de um nível para outro pode gerar equívocos na compreensão das formas de participação das crianças, uma vez que, ao implicar uma hierarquia de valores, desconsidera-se que uma forma de participação pode contemplar mais de um nível. Nessa análise também se apresenta uma desconsideração das diferenças individuais e de contextos, os quais influenciarão a participação das crianças. Além disso, seria por demasiado injusto considerar que a real participação só ocorreria a partir do nível 6 (Reddy \& Ratna, 2002; Ackermann, Feeny, Hart, \& Newman, 2003; Rizzini \& Tisdall, 2012).

Diante dessas críticas, alguns autores, como Reddy e Ratna (2002), propuseram uma releitura dos degraus da escada de Hart a partir do que chamaram de "Cenários de Compromisso Adulto-Infantil", os quais são compostos com base na interação entre adultos e crianças. Esses cenários 
permitem-nos pensar em relações mais complexas e menos estandartizadas entre adultos e crianças, diferentemente da escada de Hart. A partir dessa releitura podemos olhar a participação infantil de uma forma mais flexibilizada e sem a ideia de níveis, mas, sim, de contextos, de cenários, os quais podem variar e possibilitar uma ou mais formas de participação.

Assim, uma sociedade que busca ser democrática deve garantir a participação de todos os envolvidos, já que participar é um direito fundamental de cidadania. Além disso, com o crescimento dos direitos das crianças, temos acompanhado um aumento no reconhecimento das habilidades infantis, permitindo, assim, que as crianças falem por si mesmas (Hart, 1992; Lansdown, 2003).

Uma participação pode ser considerada realmente democrática quando:

- A criança compreende do que tratam os projetos e qual é o seu papel neles: no desenvolvimento de um projeto é imprescindível que as crianças entendam seu objetivo e a função que se espera delas em cada uma das fases de consecução das atividades para se chegar ao fim almejado.

- As relações de poder e as estruturas de tomada de decisões são transparentes: é fundamental que haja uma discussão acerca das regras que serão estabelecidas no desenvolvimento dos projetos, possibilitando, dessa forma, o compartilhamento de poder entre adultos e crianças em todas as etapas, desde o planejamento até a finalização. É tomando parte dessas etapas que as crianças terão a possibilidade de, também, participar dos processos de decisão.

- Todas as crianças são tratadas com igualdade de direitos, levandose em consideração suas idades, situações, etnias, habilidades e outros fatores: a participação deve ser inclusiva, ponderando as crianças em sua diversidade de contexto para garantir uma participação genuína de todos, inclusive das mais marginalizadas, como as crianças pobres, negras, etc.

- A participação é voluntária e as crianças têm a opção de deixar o projeto quando desejarem: considerando o compromisso ético no desenvolvimento de projetos de participação infantil, as crianças 
devem ter a liberdade de se retirarem das ações que estão sendo desenvolvidas caso percam o interesse ou decidam sair por algum outro motivo.

- São respeitadas as perspectivas e experiências infantis: para que haja uma real participação infantil, os projetos precisam levar em consideração metodologias que possam, efetivamente, captar o ponto de vista das crianças. Dessa forma, é possível aproximar-se das suas perspectivas de compreensão do mundo adulto a partir de metodologias que abordem as múltiplas linguagens, como as derivadas do campo da arte envolvendo desenho, fotografia, filmagem etc.

Considerar a criança por esse viés possibilitará o desenvolvimento de suas novas habilidades; contribuirá com a constituição de uma autoestima mais positiva; mudará o senso comum associado à ideia de impotência; reconhecerá a capacidade da criança de assumir responsabilidades individuais e sociais; fomentará o conhecimento acerca de seus direitos; possibilitará a elas que reclamem seus próprios direitos; permitirá, também, que influenciem os processos de transformação social e se constituírem como uma forma de empoderamento (Lansdown, 2003; Alfageme et al., 2003).

No entanto, também é importante tomar cuidado com a romantização ou mitificação dessa participação da criança, a qual não deve se tornar um fim em si mesma, mas, sim, possibilitar a melhoria de vida das crianças e sua relação com os outros. Assim, dar voz às crianças não é somente deixá-las falar, mas é buscar maneiras de compreender as teorizações sobre o mundo social que as perspectivas das crianças podem nos fornecer (Wyness, 2006; James, 2007).

Outro perigo associado à ideia de dar voz às crianças está em considerá-las como um grupo indistinto, ou seja, não entender as crianças a partir das questões de classe, gênero, raça/etnia, mas enxergá-las todas juntas como uma categoria. Isso pode levar ao risco de desconsiderar a variedade de mundos sociais nos quais as crianças habitam e silenciar a sua voz, mais uma vez (James, 2007). Essa é uma questão crucial que nos faz refletir acerca das ações de participação infantil, pois é muito fácil dizer que se está escutando o que as crianças têm a dizer, mas o que isso tem, efetivamente, modificado ou impactado suas vidas? Estamos levando em 
consideração as diversidades de contextos nos quais as crianças vivem? Estamos realmente criando espaços nos quais as diferentes infâncias tenham seus direitos protegidos?

Devemos pontuar que, apesar do estágio atual de consideração das crianças, ainda vivemos o que Sarmento (2005) denomina de "paradoxos da infância". Mesmo em um momento no qual as crianças estão cada vez mais presentes em pesquisas, em instituições de proteção e cuidado, elas continuam sendo as maiores vítimas das condições de exclusão, fato que é um dos paradoxos mais importantes da atualidade.

\section{Uma experiência brasileira a respeito da participação infantil e a reelaboração do espaço urbano na perspectiva das crianças}

A pesquisa realizada é caracterizada como um estudo qualitativo de base bibliográfica e documental. O estudo desenvolvido ocupou-se do levantamento de ações vinculadas aos projetos desenvolvidos pelo CECIP por meio de acesso ao site da organização, o qual disponibiliza online informações acerca de suas atividades por meio de documentos, relatórios e planos de ações. Após a coleta dos dados, esses foram organizados e analisados por meio da técnica de análise de conteúdo. É nesse sentido que caracterizamos a pesquisa enquanto bibliográfica e documental, pois, de acordo com Godoy (1995), esse tipo de estudo pode ser definido como "o exame de materiais escritos de natureza diversa, que ainda não receberam tratamento analítico ou que podem ser reexaminados, buscando-se novas interpretações" (p. 22).

É a partir do exame de materiais de natureza bibliográfica e documental que apresentamos nessa reflexão as ações de participação infantil que fazem parte de um projeto amplo do CECIP denominado "Criança Pequena em Foco", que têm como um dos seus principais objetivos fomentar estratégias de promoção da participação infantil visando reduzir a violência contra as crianças na formulação de políticas públicas. O projeto "Criança Pequena em Foco" teve início em 2011 e até o momento desenvolveu várias iniciativas em prol da participação infantil no município do Rio de Janeiro, especificamente com crianças que moram em favelas. A seguir 
apresentaremos algumas dessas iniciativas, visando contribuir para a nossa reflexão a respeito da participação infantil e das suas possibilidades de concretização.

No ano de 2013, o CECIP realizou o I Seminário "A criança e sua participação infantil", tendo um de seus principais objetivos voltados à questão da participação infantil, ou seja, incluir as crianças como participantes ativos do processo de planejamento urbano. O evento foi realizado no Instituto de Filosofia e Ciências Sociais (IFCS) da Universidade Federal do Rio de Janeiro (UFRJ), em parceria com o Laboratório de Antropologia Urbana (LAU) do IFCS, com o financiamento da Fundação Bernard van Leer e do Instituto Pereira Passos (IPP). O evento durou dois dias e, no segundo dia, as crianças foram recebidas na universidade e puderam participar de oficinas juntamente com seus pais e responsáveis, podendo propor, opinar, refletir e discutir acerca dos espaços coletivos da cidade. Diferentes metodologias foram utilizadas, considerando a organização dos grupos por faixa etária. Nessa oficina foram produzidos cartazes e desenhos, nos quais as crianças puderam apresentar suas reivindicações, desejos e sonhos para sua cidade e comunidade. As crianças também participaram da elaboração de um vídeo no qual tiveram a oportunidade de expor suas opiniões.

A proposição de atividades que transcendem o uso da linguagem oral e escrita se caracteriza como um meio alternativo de, por meio da arte, da estética, possibilitar que as crianças, mesmo as bem pequenas, também possam expressar suas ideias e opiniões. Isso também possibilita ultrapassar um modelo de participação que reproduz as instituições adultas, como os parlamentos locais ou as comissões consultivas. Nesse sentido, de acordo com Sarmento, Fernandes, e Tomás (2007), é preciso descobrir "através do recurso à imaginação interventora, modalidades de participação compatíveis com as culturas infantis, formas de comunicação atentas aos modos de expressão das crianças" (p. 196)

Uma segunda oficina foi conduzida pelas próprias crianças que participam do Grupo Mobilizador da Rede + Criança. A atividade, denominada "Vamos construir a teia da vida com as crianças da cidade?", foi realizada a partir da fala das crianças acerca de suas observações sobre o espaço da universidade. Após essa atividade, as crianças fizeram uma reflexão sobre o que gostam e não gostam nos lugares que frequentam, como escola, casa, etc. 
Uma equipe do Design for Chance conduziu a oficina "Nosso bairro", na qual as crianças puderam pensar em alternativas de melhorias para a comunidade onde moram, tendo a pergunta "Como podemos mudar nosso bairro?" como questão norteadora para a atividade. Outras duas oficinas, ainda, foram utilizando metodologias voltadas às linguagens infantis, como desenhos, brincadeiras, registros fotográficos, produção de maquetes, entrevistas (as crianças eram as repórteres), a partir das quais as crianças puderam falar e ser ouvidas, visando a elaboração de políticas públicas e projetos arquitetônicos envolvendo o espaço da cidade e da comunidade onde moram.

A partir das reflexões de Müller e Salgado (2015), pudemos constatar que os usos da arte e dos recursos associados à fotografia digital estão cada vez mais sendo utilizados na pesquisa com crianças, visando captar seus pontos de vista. E, nesse projeto citado anteriormente, vimos que o uso desses recursos pode possibilitar a expressão e a participação das crianças enquanto formas mais adaptadas ao seu universo infantil.

Durante as oficinas de construção de maquete, as crianças desenharam bairros com calçadas coloridas, casas em formatos de bota, iglus e pinguins. As crianças também expressaram sua preocupação e incômodo com o lixo em suas comunidades, bem como retrataram os espaços coletivos com muitas árvores, flores e gramados. Um espaço bastante mencionado foi a escola, do qual reclamaram de estar 'destruído' e necessitando de melhorias. Também apresentaram o recreio, as aulas de educação física e artes como os aspectos positivos da escola.

O projeto também tem como uma de suas conquistas a elaboração do Plano Municipal pela Primeira Infância (PMPI) (Centro de Criação de Imagem Popular, 2013b), construído com a participação das crianças em 2013. O PMPI do Rio de Janeiro tem como objetivo central desenvolver ações dirigidas às crianças de 0 a 6 anos, sendo norteado pelo Plano Nacional pela Primeira Infância aprovado em dezembro de 2010. Este Plano Municipal foi organizado por várias entidades integrantes da Rede Nacional Primeira Infância (RNPI), dentre elas o CECIP. O Plano Municipal possui cinco eixos prioritários, quais sejam: saúde; educação infantil; cultura, esporte e lazer; cidade/espaço urbano; e prevenção à violência contra as crianças. Para cada eixo é apresentado um panorama com dados de pesquisa e estatísticas, bem como as prioridades para sanar os problemas elencados, considerando, também, a consulta feita às crianças. 
A seguir, apresentamos o quadro 1, denominado "Consulta às Crianças", com as prioridades e o levantamento realizado junto às crianças. É importante pontuar que esse quadro está presente no documento já citado anteriormente e que se refere ao "Plano Municipal pela Primeira Infância". Nesse documento o quadro é bem mais amplo, mas considerando o espaço da presente reflexão optou-se por uma apresentação resumida do mesmo. A partir desse quadro temos a possibilidade de confirmar como as crianças têm efetivamente uma opinião sobre todos os assuntos que as afetam direta e indiretamente. Isso reforça ainda mais a ampliação das oportunidades das crianças de falarem e serem ouvidas.

A escuta das crianças foi considerada em três momentos de realização das discussões de elaboração do Plano: "a) apresentação do grupo para propiciar uma aproximação entre crianças e facilitadores; b) mapeamento dos espaços e das percepções por meio da produção de cartazes com desenhos e textos feitos pelas crianças; e c) identificação dos problemas para a construção de propostas coletivas de mudança" (Plano Municipal pela Primeira Infância, 2013, p. 5). A ação contou com a participação de crianças entre 3 e 9 anos de idade, de diferentes regiões do Rio de Janeiro, como Favela Santa Maria (Zona Sul), Morro do São Carlos (Centro), Pedra de Guaratiba e Praça Seca (Zona Oeste) e Morro do Turano (Zona Norte).

Reconhecer a capacidade das crianças falarem sobre suas próprias vidas e os fatores que estão ao seu redor potencializa a imagem de uma criança "rica" enquanto sujeito de direitos e competente. Essa imagem da criança "rica" é uma metáfora criada por Loris Malaguzzi (1998) ao relatar as experiências das crianças na educação da primeira infância em Reggio Emilia. O adjetivo, "rica", nos remete à ideia de uma criança possuidora de recursos e interesses, e que, a partir desses, constrói teorias sobre si mesma e sobre o mundo adulto que a cerca.

O projeto "Criança em foco" produziu em 2013 um guia metodológico denominado "Vamos ouvir as crianças: caderno de metodologias participativas" (Centro de Criação de Imagem Popular, 2013a). O caderno é resultado da experiência adquirida pelos profissionais envolvidos com o projeto e da participação das crianças ao longo do ano de 2012, a partir da realização de dez oficinas. Com base na divulgação desse material, busca-se difundir as metodologias utilizadas nas oficinas com a participação das 
crianças por meio da proposição de estratégias que potencializem a participação infantil, promovendo, assim, espaços de troca, falas e discussões nos quais as crianças possam apresentar seus anseios e desejos para a melhora de suas condições de vida no espaço urbano.

Quadro 1 - Consulta às crianças

\begin{tabular}{|c|c|c|c|c|c|}
\hline Eixos: & Saúde & $\begin{array}{l}\text { Educação } \\
\text { infantil }\end{array}$ & $\begin{array}{l}\text { Cultura, } \\
\text { esporte e } \\
\text { lazer }\end{array}$ & $\begin{array}{l}\text { Cidade/espaç } \\
\text { o urbano }\end{array}$ & $\begin{array}{l}\text { Prevenção à } \\
\text { violência } \\
\text { contra as } \\
\text { crianças }\end{array}$ \\
\hline \multirow{6}{*}{$\begin{array}{l}\text { Consulta às } \\
\text { crianças (fala } \\
\text { das crianças } \\
\text { sobre suas } \\
\text { percepções a } \\
\text { respeito dos } \\
\text { eixos): }\end{array}$} & $\begin{array}{l}\text { Tem pracinha, } \\
\text { parque de } \\
\text { diversão, mas } \\
\text { não tem } \\
\text { hospital }\end{array}$ & $\begin{array}{l}\text { A escola tá } \\
\text { sendo } \\
\text { assaltada }\end{array}$ & $\begin{array}{l}\text { O lugar onde } \\
\text { moro tem tiro... } \\
\text { onde eu moro } \\
\text { consigo ver as } \\
\text { nuvens }\end{array}$ & $\begin{array}{l}\text { O ônibus corre } \\
\text { pra burro }\end{array}$ & $\begin{array}{l}\text { Meu pai mora } \\
\text { no trabalho, lá } \\
\text { na Barra }\end{array}$ \\
\hline & $\begin{array}{l}\text { Na minha rua } \\
\text { não tem } \\
\text { hospital }\end{array}$ & $\begin{array}{l}\text { É chato e nem } \\
\text { tem hora de } \\
\text { brincar }\end{array}$ & $\begin{array}{l}\text { Eu gosto de } \\
\text { amarelinha e } \\
\text { pique }\end{array}$ & $\begin{array}{l}\text { Tem muito } \\
\text { atropelamento }\end{array}$ & $\begin{array}{l}\text { A comida no } \\
\text { mercado é } \\
\text { muito cara }\end{array}$ \\
\hline & $\begin{array}{l}\text { Tinha que ter } \\
\text { elevador para } \\
\text { quem tem } \\
\text { cadeira de } \\
\text { rodas }\end{array}$ & $\begin{array}{l}\text { Lá, não tem } \\
\text { jardim }\end{array}$ & $\begin{array}{l}\text { O parquinho é } \\
\text { longe da } \\
\text { minha casa }\end{array}$ & $\begin{array}{l}\text { O ônibus não } \\
\text { para nos } \\
\text { pontos }\end{array}$ & $\begin{array}{l}\text { Não precisa } \\
\text { bater, é só } \\
\text { conversar }\end{array}$ \\
\hline & $\begin{array}{l}\text { Tem muita } \\
\text { gente } \\
\text { esperando no } \\
\text { Posto }\end{array}$ & $\begin{array}{l}\text { Tinha que ter } \\
\text { sala de } \\
\text { música, } \\
\text { informática }\end{array}$ & $\begin{array}{l}\text { Quando a } \\
\text { praia está suja } \\
\text { tem que varrer } \\
\text { a areia }\end{array}$ & $\begin{array}{l}\text { Tem que ser } \\
\text { modificado, } \\
\text { colocar banco } \\
\text { menor }\end{array}$ & $\begin{array}{l}\text { Para minha } \\
\text { mãe não bater, } \\
\text { ela tinha que } \\
\text { ter mais férias } \\
\text { e descansar }\end{array}$ \\
\hline & $\begin{array}{l}\text { Tem que ter } \\
\text { mais hospital } \\
\text { perto de casa }\end{array}$ & $\begin{array}{l}\text { Tem que } \\
\text { colocar mais } \\
\text { vegetais na } \\
\text { comida }\end{array}$ & $\begin{array}{l}\text { Queria um } \\
\text { parque e um } \\
\text { prédio }\end{array}$ & $\begin{array}{l}\text { Tem que } \\
\text { colocar botões } \\
\text { nos sinais para } \\
\text { as pessoas } \\
\text { atravessarem }\end{array}$ & $\begin{array}{l}\text { Queria que } \\
\text { minha mãe } \\
\text { ficasse mais } \\
\text { comigo... } \\
\text { tivesse mais } \\
\text { tempo }\end{array}$ \\
\hline & $\begin{array}{l}\text { Pode ter } \\
\text { televisão e } \\
\text { sala para } \\
\text { brincar quando } \\
\text { tá esperando }\end{array}$ & $\begin{array}{l}\text { Quero dois } \\
\text { quadros, dois } \\
\text { armários e } \\
\text { duas } \\
\text { televisões para } \\
\text { ver filme, } \\
\text { porque a } \\
\text { televisão tá } \\
\text { ruim, porque o } \\
\text { armário é } \\
\text { pequeno, e o } \\
\text { quadro quando } \\
\text { apaga fica com } \\
\text { uma marcona }\end{array}$ & $\begin{array}{l}\text { Meus pais não } \\
\text { deixam eu } \\
\text { jogar na rua }\end{array}$ & $\begin{array}{l}\text { Os meninos } \\
\text { brincam em } \\
\text { casa, não } \\
\text { brincam na rua } \\
\text { porque não } \\
\text { pode e não } \\
\text { pode ou } \\
\text { porque pode } \\
\text { perder o } \\
\text { brinquedo e } \\
\text { ser atropelado }\end{array}$ & $\begin{array}{l}\text { Minha mãe } \\
\text { tinha que } \\
\text { dormir mais } \\
\text { um pouco, pra } \\
\text { não ficar } \\
\text { nervosa, ela } \\
\text { vive cansada }\end{array}$ \\
\hline
\end{tabular}


Müller e Salgado (2015) discutem os desafios ainda enfrentados na definição metodológica quando se considera as crianças como agentes e a busca pela escuta de suas vozes. Nesse sentido, consideramos que o guia metodológico com a proposição de ações visando possibilitar a participação das crianças pode se caracterizar como um instrumento que apresenta caminhos para o enfrentamento desse desafio apontado pelas autoras citadas anteriormente.

As oficinas do guia metodológico contam com uma organização de diversidade, considerando as faixas etárias das crianças envolvidas, as quais são divididas em grupos de quatro a doze participantes. Há a presença dos "facilitadores", que têm como principal função moderar a discussão, para que todas as crianças tenham a oportunidade de falar. As oficinas respeitam o 'tempo' do grupo e abordam assuntos que façam parte do cotidiano das crianças. A metodologia envolve a utilização de diversas linguagens, dentre elas o desenho, a ludicidade, a brincadeira, entre outras.

Essa ênfase à criatividade da criança nos processos de participação infantil é valorizada por Tisdall (2013) ao propor uma participação transformadora por meio de performances que se baseiam nas expressões culturais dos grupos das crianças e dos adolescentes, citando formas de expressão desses grupos por meio do uso de músicas, vídeos, teatro, shows, cartazes, e mídia digital, dando a possibilidade de protestar, reclamar e reivindicar melhorias em suas comunidades e que demonstram as suas preocupações com o ambiente que os cerca. Nesse sentido, concordamos com a autora ao considerar que

(...) o potencial da participação como performance leva à mudanças de atitude, propicia caminhos para a percepção dos problemas e das soluções e tem uma duração de longo efeito quando comparado a uma tradução mecânica da perspectiva das crianças e jovens dentro de uma decisão particular (Tisdall, 2013, p. 189).

O projeto "Criança em foco" contou também com realização de ações em parceria com a Prefeitura do Rio de Janeiro por meio da Companhia de Engenharia de Tráfego (CET-Rio), os quais tinham como foco o desenvolvimento de uma experiência de participação infantil piloto realizada em 2013 - "Trânsito seguro com participação das crianças pequenas" (Centro de Criação de Imagem Popular, 2013c). Essa experiência foi feita em uma 
escola da favela do Complexo do Alemão, visando prevenir os acidentes de trânsito, dos quais as crianças são as maiores vítimas. Nesse cenário, levouse em consideração, além da participação das crianças de seis anos, os pais, a comunidade e o poder público. Durante o processo foram realizadas três oficinas com crianças do primeiro ano do ensino fundamental, com o objetivo de contribuir para uma reflexão, no grupo de crianças, sobre o caminho que percorriam de suas casas até a escola. Assim, "a partir do levantamento de hipóteses e questões, estimulá-las a pensarem em soluções para os problemas que venham a identificar. Como solução para um desses problemas - o desrespeito ao sinal próximo à escola -, as crianças sugeriram a colocação de uma placa com os dizeres: 'respeite o sinal'" (Centro de Criação de Imagem Popular, 2013c, p. 5).

Essas oficinas apontam para a perspectiva de um trabalho baseado na ideia de co-produção. De acordo com Tisdall (2013), esse processo de participação, tendo como um de seus princípios a co-produção, gera um trabalho colaborativo, propicia um envolvimento mais profundo e demonstra que adultos podem, de forma produtiva, trabalhar junto com as crianças.

O projeto desenvolveu também uma pesquisa denominada "Infância e Favela: a perspectiva das crianças sobre o lugar onde vivem", coordenada pelas pesquisadoras Beatriz Corsino, Maria Dantas Jardim e Anna Rosa Amâncio. O projeto tinha como principais objetivos conhecer a realidade das crianças, promover um espaço de fala e de troca entre as crianças e o poder público, bem como desenvolver metodologias participativas de trabalho com crianças pequenas que possam ser replicadas e adaptadas. A metodologia utilizada gerou uma oficina com crianças do Morro da Babilônia e de Santa Marta, de idades que variam de 4 a 12 anos, totalizando 100 participantes. As oficinas tiveram como eixos centrais ouvir a perspectiva das crianças sobre os seguintes assuntos: a opinião sobre suas escolas; as brincadeiras e os usos dos espaços da favela; os principais problemas do lugar onde vivem e como lidam com a obra do "Morar Carioca". Os resultados da pesquisa demonstraram que as crianças desejam uma escola melhor e mais bonita e que uma escola boa "é aquela que as deixa brincar, que passa dever e onde elas podem aprender muitas coisas" (Relatório da pesquisa, 2012, p. 4). As crianças disseram brincar de jogos, pipa, pique esconde, subir em árvores e brincar em vários espaços da favela como becos, vielas, campinhos, etc. 
Em 2012, foi desenvolvida uma atividade no Morro Santa Marta, a qual originou o projeto "A comunidade Santa Marta pelo olhar das crianças". Nele, as crianças com entre 4 e 5 anos de idade realizaram dois passeios pela comunidade e fotografaram os espaços considerados por elas como os mais significativos, buscando, assim, identificar a relação das crianças com o espaço em que vivem. De acordo com o relatório, "as fotografias evidenciam que a perspectiva das crianças tem muito a contribuir para a transformação da realidade e deveriam ser consideradas por arquitetos e urbanistas para o planejamento da cidade" (Relatório do projeto "A comunidade Santa Marta pelo olhar das crianças", 2012, p. 1).

A partir dos projetos e ações relatados nesse estudo foi possível perceber a preocupação dos organizadores em considerar os assuntos que estão diretamente implicados na vida das crianças, ou seja, são aspectos que os preocupam e que demandam uma solução visando a melhoria da qualidade de vida da comunidade. Por isso, segundo Tomás (2007), o discurso e a prática dos adultos envolvidos em projetos de participação infantil "deverão preocupar-se com as questões de competências, com os sentimentos de pertença e implicação na comunidade, e outros temas do interesse das crianças, em vez de continuarem centrados na discussão sobre a situação de dependência e tutela em que as crianças vivem" (p. 65).

Essa última reflexão da autora, ao apresentar a importância de desconstruirmos essa visão da criança enquanto dependente e tutelado, é fundamental quando consideramos os sujeitos-crianças que participaram desses projetos desenvolvidos pelo CECIP, pois são crianças que moram em um contexto social bastante estigmatizado pela pobreza e a violência. Nesse sentido é que afirmamos a importância de ações que resignifiquem esse lugar social e essa criança, também vista negativamente pela sociedade, no sentido de "empoderar", ao possibilitar o desenvolvimento de competências e habilidades infantis enquanto formas de emancipação.

Uma discussão muito importante que deve ser considerada ao propormos formas de participação das crianças a partir de atividades propostas pelos adultos é a questão da ética. Por meio dos documentos que trouxemos para discutir os projetos desenvolvidos pelo CECIP, não encontramos menção a tal assunto, mas precisamos pontuar alguns aspectos sobre o mesmo. 
Proteger as crianças de projetos abusivos e que as exploram é um fator a ser sempre considerado, pois as relações de poder serão sempre inerentes na interação entre adultos e crianças; assim, a reflexão acerca dos papéis e funções que cada sujeito deverá desempenhar no desenvolvimento de um projeto deve ser redimensionado e revisto o tempo todo a partir de uma relação de negociação entre todos os sujeitos envolvidos.

Müller e Salgado (2015) se colocam algumas questões acerca da ética na pesquisa com crianças e que nos auxiliam a pensar na relação entre adultos e crianças no processo de desenvolvimento de projetos de participação infantil, que são as seguintes:

Tenho tempo para construir um relacionamento significativo com a criança, onde ela possa se sentir mais confortável para mostrar seus pontos de vista e opiniões? Se eu construí um relacionamento com a criança, qual o impacto que isso terá sobre a minha capacidade de ser objetivo no processo de geração de dados, ou no processo de co-construção? (p. 116).

As autoras discutem acerca da relação estabelecida entre crianças e adultos e o quanto essa relação pode ser problemática, por isso apresenta tantos desafios ao pesquisador. No caso da nossa reflexão, apontam para os desafios enfrentados pelos adultos que elaboram projetos com crianças ao executarem propostas de participação infantil. Apontam também "para o cuidado com certas práticas que se faz necessário para não tornar a participação das crianças em algo ilusório e falhar no impacto que essa participação deve ter nos processos decisórios que afetam a vida das crianças e jovens" (Tisdall, 2013, p. 188).

A partir dessa descrição das atividades do CECIP, buscamos criar um espaço de reflexão sobre as possibilidades de fomentar a participação infantil. Nos projetos apresentados, as crianças foram convidadas a fazer parte e foram consultadas a respeito de vários aspectos relacionados à sua relação com a cidade do Rio de Janeiro e com seu entorno.

\section{Considerações finais}

A experiência brasileira que trouxemos aponta caminhos importantes na consideração da participação infantil nos espaços públicos, especificamente nos urbanos. Os projetos envolvendo as crianças e seus contextos de vida contribuem para a consideração delas como cidadãs ativas 
e competentes e nos mostram que essas estão bastante atentas ao espaço que as rodeia.

A metodologia utilizada no desenvolvimento dos projetos do CECIP mostrou que é possível dar voz às crianças, a partir do momento em que consideram suas culturas, através da utilização de procedimentos mais apropriados às linguagens infantis - como, por exemplo, as brincadeiras, os desenhos, a confecção de cartazes e maquetes, a utilização da fotografia, etc. Isso contribui para a não reprodução de práticas adultocêntricas nos processos que envolvem a participação infantil.

Todos os projetos foram desenvolvidos com crianças que residem em favelas e, por meio dessas ações, os participantes puderam apresentar os espaços que mais gostam e também aqueles que precisam de investimentos para que se tornem mais organizados e funcionais. Nos desenhos realizados, as crianças manifestaram o desejo de viver em um espaço arborizado e com jardins, com parques, já que é perigoso brincar na rua, solicitaram hospitais e espaços adaptados.

A participação das crianças nesses projetos lhes possibilita tomar parte de processos nos quais, historicamente, suas decisões referentes ao espaço urbano eram desconsideradas, podendo, assim, contribuir para o planejamento e constituição de políticas públicas, abrindo um espaço importante para a afirmação de uma democracia participativa. Nesse sentido, os projetos desenvolvidos incluem as crianças pobres e, em sua maioria, negras, que vivem em espaços estigmatizados, como é o caso das favelas, por exemplo. A participação infantil deve ser inclusiva para que realmente possa contribuir com a concretização da cidadania de todas as crianças.

Por meio dos dados encontrados nas atividades desenvolvidas no âmbito do projeto "Crianças em Foco", abre-se a possibilidade para o "empoderamento" das crianças na sua relação com o espaço da cidade. Esse "empoderamento" passa pela promessa de participação das crianças em projetos que Ihes são significativos e que Ihes dizem respeito diretamente. As crianças apresentam clareza acerca das condições em que vivem e dos aspectos necessários para a alteração desses espaços que lhes são significativos. Assim, por meio da expressão de sua opinião e da proposição de ações, as crianças apontam caminhos para os elaboradores de políticas públicas na consecução de projetos voltados aos espaços urbanos. 


\section{Referências}

Ackermann, L., Feeny, T., Hart, J., \& Newman, J. (2003). Understanding and evaluating children's participation: A review of contemporary literature. UK: Plan International.

Alfageme, E., Cantos, R., \& Martínez, M. (2003). De la participación al protagonismo infantil: Propuestas para la acción. Madrid: Plataforma de Organizaciones de Infancia.

Centro de Criação de Imagem Popular (2013a). Guia metodológico: "Vamos ouvir as crianças: Caderno de metodologias participativas". Rio de Janeiro: CECIP. Disponível em: www.cecip.org.br (acessado em 8 de agosto de 2015).

Centro de Criação de Imagem Popular (2013b). Plano municipal pela primeira infância. Rio de Janeiro: CECIP. Disponível em: www.cecip.org.br (acessado em 8 de agosto de 2015).

Centro de Criação de Imagem Popular (2013c). Relatório parceira CET-Rio: Trânsito seguro com participação das crianças pequenas. Rio de Janeiro: CECIP. Disponível em: www.cecip.org.br (acessado em 8 de agosto de 2015).

Godoy, A. S. (1995). Pesquisa qualitativa: Tipos fundamentais. RAE - Revista de Administração de Empresas, 35(3), 20-29.

Hart, R. A. (1992). Children's participation: From tokenism to citizenship. Italy: Unicef International Child Development Centre Spedale degli Innocenti.

James, A. (2007). Giving voice to children's voices: Practices and problems, pitfalls and potentials. American Anthropologist, 19(2), 261-272.

James, A., \& Prout, A. (Orgs.). (1990). Constructing and reconstructing childhood: Contemporary issues in the sociological study of childhood. Londres: The Falmer Press.

Lansdown, G. (2001). Promoting children's participation in democratic decision-making. Italy: Arti Grafiche Ticci.

Malaguzzi, L. (1998). History, ideas and basic philosophy. In L. G. Edwards \& G. Forman (Orgs), The hundred languages of children: The Reggio Emilia approach. (2nd ed.) (pp. 49-97). Greenwich: Ablex.

Mollo-Bouvier, S. (2005). Transformação dos modos de socialização das crianças: Uma abordagem sociológica. Educação \& Sociedade, 91(26), 391-404.

Montandon, C. (2001). Sociologia da infância: Balanços dos trabalhos de língua inglesa. Cadernos de Pesquisa, 112, 33-60.

Müller, F., \& Salgado, M. M. (2015). A participação das crianças nos estudos da infância e as possibilidades da etnografia sensorial. Currículo sem Fronteiras, 15(1), 107-126.

Plaisance, E. (2004). Para uma sociologia da pequena infância. Educação \& Sociedade, 25(86), 221-241.

Reddy, N. \& Ratna, R. (2002). A journey in children's participation. India: Concerned for working children. Retirado de: http://www.pronats.de/assets/upload/reddy-ratnaa-journey-in-children-participation.pdf

Rizzini, I., \& Tisdall, K. (2012). Introdução: A importância do debate internacional e 
interdisciplinar sobre participação infantil e juvenil. O Social em Questão, Ano $\mathrm{XV}, \mathrm{n}^{\circ} 27,15-20$.

Sarmento, M. J. (2005). Gerações e alteridade: Interrogações a partir da sociologia da infância. Revista Educação \& Sociedade, 26(91), 361-378.

Sarmento, M. J., \& Pinto, M. (1997). As crianças e a infância: Definindo conceitos delimitando o campo. In M. J. Sarmento \& M. Pinto (Orgs.), As crianças: Contextos e identidades (pp. 9-30). Braga: Instituto de Estudos da Criança da Universidade do Minho.

Sarmento, M. J., Fernandes, N., \& Tomás, C. (2007). Políticas públicas e participação infantil. Educação, Sociedade \& Culturas, 25, 183-206.

Sirota, R. (2001). Emergência de uma sociologia da infância: Evolução do objeto e do olhar. Cadernos de Pesquisa, 112, 7-31.

Suriel, A. (2006). Derecho a la participación de los niños, niñas y adolescentes: Guía práctica para su aplicación. Santo Domingo/República Dominicana: UNICEF.

Taylor, M., \& Percy-Smith, B. (2008). Children's participation: Learning from and for community development. International Journal of Children's Rights, 16, 379394.

Tisdall, E. K. M. (2013). The transformation of participation? Exploring the potential of 'transformative participation' for theory and practice around children and young people's participation. Global Studies of Children, 3(2), 183-193.

Tomás, C. (2007). "Participação não tem idade": Participação das crianças e cidadania da infância. Contexto \& Educação, ano 22, no 78, 45-68.

Wyness, M. (2006). Childhood and society: An introduction to the sociology of childhood. London: Palgrave Macmillan. 


\section{CONSIDERATIONS ABOUT AN EXPERIENCE OF CHILDREN PARTICIPATION IN URBAN AREAS IN BRAZIL AND THEIR PERSPECTIVE ABOUT IT}

\section{Abstract}

The aim of the current study is to address child participation according to actions taken by a Brazilian non-governmental organization. The developed research is featured as qualitative due to the conduction of a bibliographic and documental study and to the consequent content analysis. It is known that studies focused on child participation, as well as the contributions from the Childhood Sociology, allow thinking about the way children act in society by understanding them as social actors, as subjects with rights and voice. The Brazilian experience we brought to the current study shows important paths about children's participation in public areas, mainly in urban areas. Projects about children and their life contexts give children the status of active and competent citizens, and show them as very attentive to the space around them.

Keywords

Child participation; Rights; Child; Childhood

\section{REFLEXIONES SOBRE UNA EXPERIENCIA DE PARTICIPACIÓN INFANTIL EN BRASIL ENVOLVIENDO LOS ESPACIOS URBANOS Y LA PERSPECTIVA DE LOS NIÑOS}

\section{Resumen}

Este trabajo tiene como objetivo reflexionar sobre la participación infantil a partir de las acciones desarrolladas por una organización no gubernamental brasileña. La investigación desarrollada se caracteriza como cualitativa a través de la realización de un estudio bibliográfico y documental, por lo consiguiente, análisis de contenido. Se entiende que a través de los Estudios de Niños, especialmente a partir de las contribuciones de la Sociología de la 
Infancia, será posible pensar en formas de actuación de los niños en la sociedad a partir de su comprensión como actor social, sujeto de derechos y con voz. La experiencia brasileña que hemos traído nos apunta caminos importantes en la consideración de la participación infantil en los espacios públicos, específicamente en el espacio urbano de las ciudades. Los proyectos desarrollados con los niños y sus contextos de vida contribuyen para su consideración como ciudadanos activos y competentes y nos enseñan que ellos están muy atentos al espacio que les rodea.

Palabras-clave

Participación infantil; Derechos; Niños; Infancia

Recebido em fevereiro/2016

Aceite para publicação em setembro/2016

i Programa de Pos-Graduação em Educação, Instituto de Ciências Humanas e Letras, Universidade Federal de Alfenas, Brasil.

Toda a correspondência relativa a este artigo deve ser enviada para: Fabiana de Oliveira, Universidade Federal de Alfenas, Rua Dr. Gabriel Monteiro, 700 - Centro - Cep: 37130-000 Alfenas - MG - Brasil. Email: fabiana.oliveiraunifal@gmail.com 